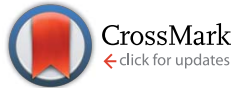

Cite this: RSC Adv., 2017, 7, 17670

\section{Dynamics of naphthenic acids and microbial community structures in a membrane bioreactor treating oil sands process-affected water: impacts of supplemented inorganic nitrogen and hydraulic retention time $\uparrow$}

\begin{abstract}
Jinkai Xue, ${ }^{a}$ Yanyan Zhang, ${ }^{\text {ab }}$ Yang Liu ${ }^{\star a}$ and Mohamed Gamal El-Din*a
This study was focused on how different operating conditions affected the biodegradation of naphthenic acids (NAs) and the microbial community architectures in an anoxic-aerobic membrane bioreactor (MBR) for oil sands process-affected water (OSPW) treatment. After 442 days of continuous optimization, a supplemented $\mathrm{NH}_{4}-\mathrm{N}$ concentration of $25 \mathrm{mg} \mathrm{L}^{-1}$ and a hydraulic retention time (HRT) of $12 \mathrm{~h}$ demonstrated the best removal rates of total classical NAs (37.6\%) and total oxidized NAs (23.9\%). Neither higher HRTs nor higher supplemented $\mathrm{NH}_{4}-\mathrm{N}$ concentrations resulted in a better overall removal of NAs. In addition, NAs with larger carbon numbers were generally better degraded, whereas higher cyclicity tended to lessen the biodegradability of NAs. MiSeq sequencing analysis disclosed that orders under Proteobacteria (i.e., Rhodocyclales, Burkholderiales and Nitrosomonadales), Bacteroidetes (i.e., Cytophagales, [Saprospirales] and Flavobacteriales), and Nitrospirae (i.e., Nitrospirales) were the major microbes over the whole study though their relative abundances varied. The results of this study provide insightful information for future studies and application of biological processes for OSPW treatment on a large scale.
\end{abstract}

Received 14th February 2017 Accepted 15th March 2017

DOI: $10.1039 / \mathrm{c} 7 \mathrm{ra01836c}$

rsc.li/rsc-advances caused by the formation of rings or double bond equivalents, ${ }^{4,10}$ and $x$ refers to the number of oxygen atoms. Species with $x=2$ are referred to as classical NAs, while those with $x \geq 3$ are termed oxidized NAs (oxy-NAs). ${ }^{11}$ It has been estimated that more than 20000 individual NAs are potentially associated with OSPW..$^{12}$ Hanging on the ore composition, extraction processes, the tailings age and quantification approaches, the NAs concentrations reportedly varied greatly within the range of 20$120 \mathrm{mg} \mathrm{L}^{-1} .^{3,13-15}$ It has been suggested that NAs with a carbon number $n \leq 21$ and/or linearly grouped carbon rings may be more toxic in OSPW; ${ }^{4,16-18}$ whereas NAs with ring structures tend to be more persistent in environment. ${ }^{2}$ It is, therefore, desirable to remove NAs from OSPW to mitigate its environment impact.

It is suggested that biodegradation is responsible for the natural, but slow dissipation of NAs in tailings ponds. ${ }^{19}$ However, the in situ biodegradation half-lives of NAs are within a range of 12.8-13.6 years. ${ }^{20}$ To accelerate the biodegradation of OSPW NAs, it is crucial to develop engineered biological processes that are efficient in mitigating OSPW organic compounds. Choi and Liu performed a study on the treatment of OSPW by using two sequencing batch reactors (SBRs) and achieved an acid extractable fraction (AEF) removal rate of 8.7\% and $16.6 \%$ at a hydraulic retention time (HRT) of $24 \mathrm{~h}$ with the inoculation of activated sludge and mature fine tailings (MFT), respectively. ${ }^{6}$ Hwang et al. reported that $13.8 \%$ of OSPW AEF and $18.5 \%$ of the OSPW parent NAs were eliminated by OSPW 
indigenous microorganisms in a biofilm reactor with an HRT of $19 \mathrm{~h}^{7}$ Hence, it is suggestive that disparate reactor configurations have different capabilities in degrading OSPW organic substances. .,21,22 $^{2}$

Membrane bioreactor (MBR) is finding wider application for municipal and industrial wastewater treatment because of its compactness, high treatment capacity, low sludge production and excellent effluent quality. ${ }^{23,24}$ To investigate the feasibility of MBR for OSPW treatment, an anoxic-aerobic MBR system was performed at an HRT of $48 \mathrm{~h}$, and attained an OSPW NA removal of $25 \%$ after the startup period (day $1-425$ ). ${ }^{25}$ To further improve its performance for OSPW treatment, more effort is needed to optimize the operating conditions.

HRT is one of the essential parameters in MBR operation. It not only affects the extent to which the target contaminants are degraded, ${ }^{26}$ but also profoundly impacts membrane fouling development. ${ }^{27,28}$ Longer HRTs are usually required for industrial wastewater, especially those containing complex organic contaminants..$^{29}$ However, the effect of HRT on the degradation of organic pollutants was still unclear as indicated by some studies. ${ }^{28,30-32}$ On the other hand, a shorter HRT is favorable as it reduces the required reactor volume (less investment) for the same treatment capacity. In addition, HRT has an indirect yet profound impact on membrane fouling through altering of sludge properties (i.e., the concentration of mixed liquor suspended solids (MLSS), the production of extracellular polymeric substances (EPS) and the viscosity of sludge). ${ }^{33-35}$ Due to increased membrane flux, shortened HRTs usually result in severer membrane fouling, ${ }^{27,28,33}$ which could increase the operating cost substantially. Therefore, a balance between contaminant removal and operation cost must be considered for HRT selection. ${ }^{29}$

Further, ammonia monooxygenase (amo) produced by ammonia oxidizing bacteria (AOB) is able to degrade a wide spectrum of refractory organic substrates (including hydrocarbons) through co-metabolism. ${ }^{36-40}$ Nitrifiers are not necessarily stimulated by higher ammonium nitrogen $\left(\mathrm{NH}_{4}-\mathrm{N}\right)$ concentrations as free ammonia (FA) is inhibitory to many microbial activities including nitrification. ${ }^{41}$ Given the alkaline nature of OSPW, the effect of FA should not be ignored. Therefore, it is needed to find out an optimal supplemented $\mathrm{NH}_{4}-\mathrm{N}$ concentration to maximize the MBR's performance of NA degradation.

The objectives of this study were: (1) to explore the optimal operation conditions to improve the MBR's NA degradation efficiency; and (2) to characterize the microbial community structure in the MBR with the aim of uncovering the most effective bacterial groups associated with NA removal. According to our literature search, this is the very first study evaluating the performance (particularly the biodegradation of classical and oxy-NAs) and characterizing the microbial communities of an MBR for OSPW treatment under various operating conditions.

\section{Methodology}

2.1 Source waters, external carbon source and supplemented nutrients

The OSPW was collected from the same tailings pond in Northern Alberta region. The OSPW used for the optimization operation had a $\mathrm{pH}$ of $8.8 \pm 0.3$, chemical oxygen demand (COD) of $224.1 \pm 46.3 \mathrm{mg} \mathrm{\textrm {L } ^ { - 1 }}, 5$ day biochemical oxygen demand $\left(\mathrm{BOD}_{5}\right)$ of $5.4 \pm 0.8 \mathrm{mg} \mathrm{L}{ }^{-1}$, classical NAs of $49.9 \pm$ $4.0 \mathrm{mg} \mathrm{L}^{-1}$, and oxy-NAs of $39.8 \pm 4.2 \mathrm{mg} \mathrm{L}^{-1}$. Raw OSPW was received in 200 liter barrels and preserved in dark at $4{ }^{\circ} \mathrm{C}$ prior to treatment. To facilitate the growth of microorganisms in the system, sodium acetate was supplied as an external carbon (C) source at a constant organic loading rate (OLR) of $125 \mathrm{~g}$ COD per $\left(\mathrm{m}^{3} \mathrm{~d}\right)$ throughout the whole operation. To ensure the sufficiency of nitrogen $(\mathrm{N})$, phosphorus $(\mathrm{P})$, and other trace nutrients, supplemented $\mathrm{KNO}_{3}, \mathrm{NH}_{4} \mathrm{Cl}, \mathrm{NaH}_{2} \mathrm{PO}_{4}$, and modified Bushnell-Haas medium (BHM) ${ }^{17}$ without $\mathrm{KH}_{2} \mathrm{PO}_{4}, \mathrm{Na}_{2} \mathrm{HPO}_{4}$, $\mathrm{NH}_{4} \mathrm{NO}_{3}$, and $\left(\mathrm{NH}_{4}\right)_{2} \mathrm{SO}_{4}$ were added in the feed water. To avoid undesirable microbial growth in the feed tank, the stock solution of external $\mathrm{C}$ source, and the stock solution of external $\mathrm{N}$ (to achieve equivalently $75 \mathrm{mg} \mathrm{N}$ per L in the feed) and $\mathrm{P}$ (to achieve equivalently $10 \mathrm{mg} \mathrm{P}$ per $\mathrm{L}$ in the feed) source were continuously injected in the MBR at a pre-set rate by using a syringe pump (KDS Infusion Pump, Model 220, KDS Scientific Inc., USA).

\subsection{MBR configuration and operating conditions}

The configuration of the MBR is illustrated in Fig. S1. $\dagger$ Detailed description on the system configuration, biomass inoculation and acclimatization is available elsewhere. ${ }^{25,42}$ Dissolved oxygen (DO) concentrations in the anoxic tank and the aerobic tank were maintained at a level of $<0.3 \mathrm{mg} \mathrm{L}^{-1}$ and $>4.0 \mathrm{mg} \mathrm{L}^{-1}$, respectively. The retentate in the aerobic tank was recirculated to the anoxic tank by overflow at a recycling ratio of 2.

The different operating conditions examined in this study are tabulated in Table 1. Despite the changes made to $\mathrm{NO}_{3}-\mathrm{N}$ and $\mathrm{NH}_{4}-\mathrm{N}$ concentrations, the total inorganic nitrogen (TIN, i.e., $\mathrm{NH}_{4}-\mathrm{N}, \mathrm{NO}_{2}-\mathrm{N}$ and $\mathrm{NO}_{3}-\mathrm{N}$ ) concentration supplemented to the system was maintained at $75 \mathrm{mg} \mathrm{N}$ per L throughout the study. The system automatically performed a 30 second backwashing after every 9.5 minutes of membrane filtration, comprising a 10 minute working phase. The relaxation duration between two working phases was adjusted to achieve a desired equivalent HRT. According to the manufacturer's suggestion, chemical cleaning (soaking the membrane module in $0.1 \%$ HClO solution for 1 hour followed by rinsing with running tap water) was applied once the transmembrane pressure (TMP)

Table 1 Operating conditions examined

Supplemented nitrogen

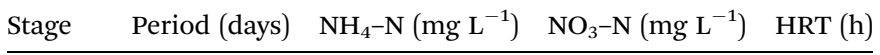

$\begin{array}{lllll}\mathrm{A} 25 \mathrm{H} 48 & 300-449 & 25 & 50 & 48\end{array}$

$\begin{array}{lllll}\text { A75H48 } & 449-546 & 75 & 0 & 48\end{array}$

$\begin{array}{lllll}\mathrm{A} 50 \mathrm{H} 48 & 546-630 & 50 & 25 & 48\end{array}$

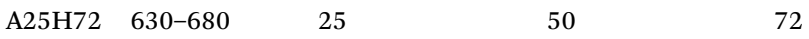

$\begin{array}{lllll}\mathrm{A} 25 \mathrm{H} 12 & 680-712 & 25 & 50 & 12\end{array}$

$\begin{array}{lllll}\mathrm{A} 25 \mathrm{H} 24 & 712-742 & 25 & 50 & 24\end{array}$ 
exceeded $-35 \mathrm{kPa}$ (severe fouling event). Sludge in the MBR was wasted through weekly sampling $(30 \mathrm{~mL}$ from each tank for solids content measurements) to achieve a calculated solid retention time (SRT) of $\sim 187$ days.

\subsection{Analyses}

Methods of conventional water chemistry analyses and acute aquatic toxicity bioassay are described in the (ESI $\dagger$ ).

2.3.1 NA measurement. To assess the MBR performance on OSPW NA degradation, ultra-performance liquid chromatography coupled with high-resolution mass spectrometry (UPLC/ HRMS $)^{11}$ was performed to quantify classical and oxy-NAs in the feed and permeate samples at the end of each operating condition stage. With respect to permeate sampling, a volume of $10 \mathrm{~mL}$ was collected from totally $2.4 \mathrm{~L}$ of permeate water produced over three consecutive days for UPLC/HMRS analysis. The second of the three days was used as the nominal sampling date. To evaluate the MBR's NA degradation performance, percentile removal rates were calculated using the initial and remaining concentrations.

2.3.2 MiSeq sequencing. A PowerSoil® DNA Isolation Kit from Mo-Bio Laboratories, Inc. (CA, USA) was used to extract DNA from collected sludge samples according to the manufacturer's manual. In addition, the fouling layer on the membrane surface was carefully scraped off by using a spatula and collected for DNA extraction. Extracted DNA samples were diluted to a concentration of $\sim 20 \mathrm{ng} \mu \mathrm{L}^{-1}$ before sending to a commercial laboratory (Research and Testing Laboratory, Texas, US). Samples were sequenced using Illumina MiSeq sequencing instruments and reagents according to the manufacturer's guidelines. Primers used for DNA amplification prior to MiSeq sequencing were $28 \mathrm{~F}$ (GAGTTTGATCNTGGCTCAG) and 388R (TGCTGCCTCCCGTAGGAGT). Raw sequence data were processed with the Quantitative Insights Into Microbial Ecology (QIIME, http://qiime.org) software package with default settings. Operational taxonomic units (OTUs) were picked through using open-reference clustering algorithm. More details are given in our published reports. ${ }^{25,42}$

2.3.3 Statistical method. Paired two sample $t$-test was used in this study to compare the MBR performance under different operating conditions with the significance level of 0.05. Pearson correlation coefficient $\left(r_{\mathrm{p}}\right)$ was used to estimate linear correlations. The coefficient $r_{\mathrm{p}}$ is a numerical value within the range of -1 and 1 that expresses the strength of the linear relationship between two parameters. An $r_{\mathrm{p}}$ closer to 1 indicates a strong positive correlation. An $r_{\mathrm{p}}$ of 0 signalize that there is no relationship. Values closer to -1 indicate a strong negative relationship between the two variables.

\section{Results and discussion}

\subsection{Classical and oxidized NA removal performance}

Table 2 presents total classical NAs concentrations of the feeds and permeates under different conditions and the estimated half-life of classical NAs under each condition. By degrading $37.6 \%$ of classical NAs within 12 h, A25H12 stage demonstrated the shortest half-life (i.e., $17.6 \mathrm{~h}$ ) of the contaminants among the six stages. In contrast, $\mathrm{A} 25 \mathrm{H} 72$ achieved the longest half-life (i.e., $159.7 \mathrm{~h}$ ) of classical NAs by removing $26.8 \%$ within $72 \mathrm{~h}$. The half-lives of classical NAs in all the six operating conditions were substantially shorter than the estimated half-life of 44-240 days in Mahdavi et al. ${ }^{\mathbf{4 3}}$ and Han et al. ' $^{\mathbf{1 4}}$ suspended biological systems, and even negligible compared with the estimated $\sim 13$ year in situ half-life in tailings ponds. ${ }^{20}$ The shortest half-life exhibited by our previous batch suspended reactors was 20 days. ${ }^{44}$ In Hwang et al.'s continuous biofilm reactor, $18.5 \%$ of classical NAs was removed within $19 \mathrm{~h}$ (half-life $=64.4 \mathrm{~h}$ ). ${ }^{7}$ More recently Huang et al.'s, integrated fixed-film activated sludge system (IFAS) demonstrated a half-life of $59.0 \mathrm{~h}$ of classical NAs. ${ }^{45}$ Therefore, the performance of MBR for OSPW NA degradation could be advantageous over conventional activated sludge systems and biofilm reactors.

Fig. 1 is prepared to examine the effect of $n$ and $Z$ on biodegradation of NAs. A relative abundance of residual classical NAs $\left(\mathrm{NA}_{\sum n \mathrm{e}} / \mathrm{NA}_{\sum n \mathrm{i}}\right)$ is used to indicate the extent of biodegradation of NAs with each $n$. $\mathrm{NA}_{\sum n \text { e }}$ denotes the total concentration of NAs with the same carbon number $n$ in the effluent, while $\mathrm{NA}_{\sum n \mathrm{i}}$ is the total concentration of NAs with the same $n$ in the influent. Therefore, a lower $\mathrm{NA}_{\sum n \mathrm{e}} / \mathrm{NA}_{\sum n \mathrm{i}}$ means a better removal of the group of NAs with $n$. Similarly, a relative abundance of residual classical NAs $\left(\mathrm{NA}_{\sum|Z| \mathrm{e}} / \mathrm{NA}_{\sum|Z| \mathrm{i}}\right)$ is used to indicate the extent of biodegradation of NAs with each $|Z|$. To better disclose how molecular $n$ and $|Z|$ affected the degradation of NAs, Fig. 2 and 3, and Fig. S3 and S4 $\dagger$ are plotted based on the NA concentration profiles.

Although the stages differed in operating conditions, similar patterns could be seen for $\mathrm{NA}_{\sum n e} / \mathrm{NA}_{\sum n \text { i }}$ over the $n$ range in Fig. 1A and B. For C9-12 and C19-23, a higher $\mathrm{NA}_{\sum n \mathrm{e}} / \mathrm{NA}_{\sum n \mathrm{i}}$ ratio is associated with a lower $n$, whereas a plateau or a slightly climbing trend of the $\mathrm{NA}_{\sum n \mathrm{e}} / \mathrm{NA}_{\sum n \mathrm{i}}$ ratio is observed when $n$ increases from 13 to 18 in Fig. 1A and B. As demonstrated in Fig. 2 and $\mathrm{S} 3, \dagger$ species with more carbon numbers were generally better degraded within each $Z$ series, which is in agreement with our previous batch study. ${ }^{44}$ In contrast, previous studies indicated that $n$ has either negatively proportional correlation to or minor influence on biodegradation of NAs. ${ }^{14,17,46}$ This discrepancy evidences that the capabilities of biological systems are considerably influenced by their

Table 2 Total classical NA concentrations of the MBR feed and permeate under different operating conditions

\begin{tabular}{|c|c|c|c|c|}
\hline \multirow{2}{*}{$\begin{array}{l}\text { Operating } \\
\text { condition }\end{array}$} & \multicolumn{2}{|c|}{$\begin{array}{l}\text { Classical NAs } \\
\left(\mathrm{mg} \mathrm{L}^{-1}\right)\end{array}$} & \multirow{2}{*}{$\begin{array}{l}\text { Removal } \\
(\%)\end{array}$} & \multirow{2}{*}{$\begin{array}{l}\text { Estimated half-life } \\
\text { (h) }\end{array}$} \\
\hline & Feed & Permeate & & \\
\hline A75H48 & 45.3 & 34.9 & 23.0 & 127.6 \\
\hline A50H48 & 51.8 & 35.9 & 30.7 & 90.7 \\
\hline A25H48 & 51.4 & 34.1 & 33.7 & 81.1 \\
\hline A25H72 & 44.7 & 32.7 & 26.8 & 159.7 \\
\hline A25H24 & 55.3 & 35.4 & 36.0 & 37.3 \\
\hline A25H12 & 44.7 & 27.9 & 37.6 & 17.6 \\
\hline
\end{tabular}



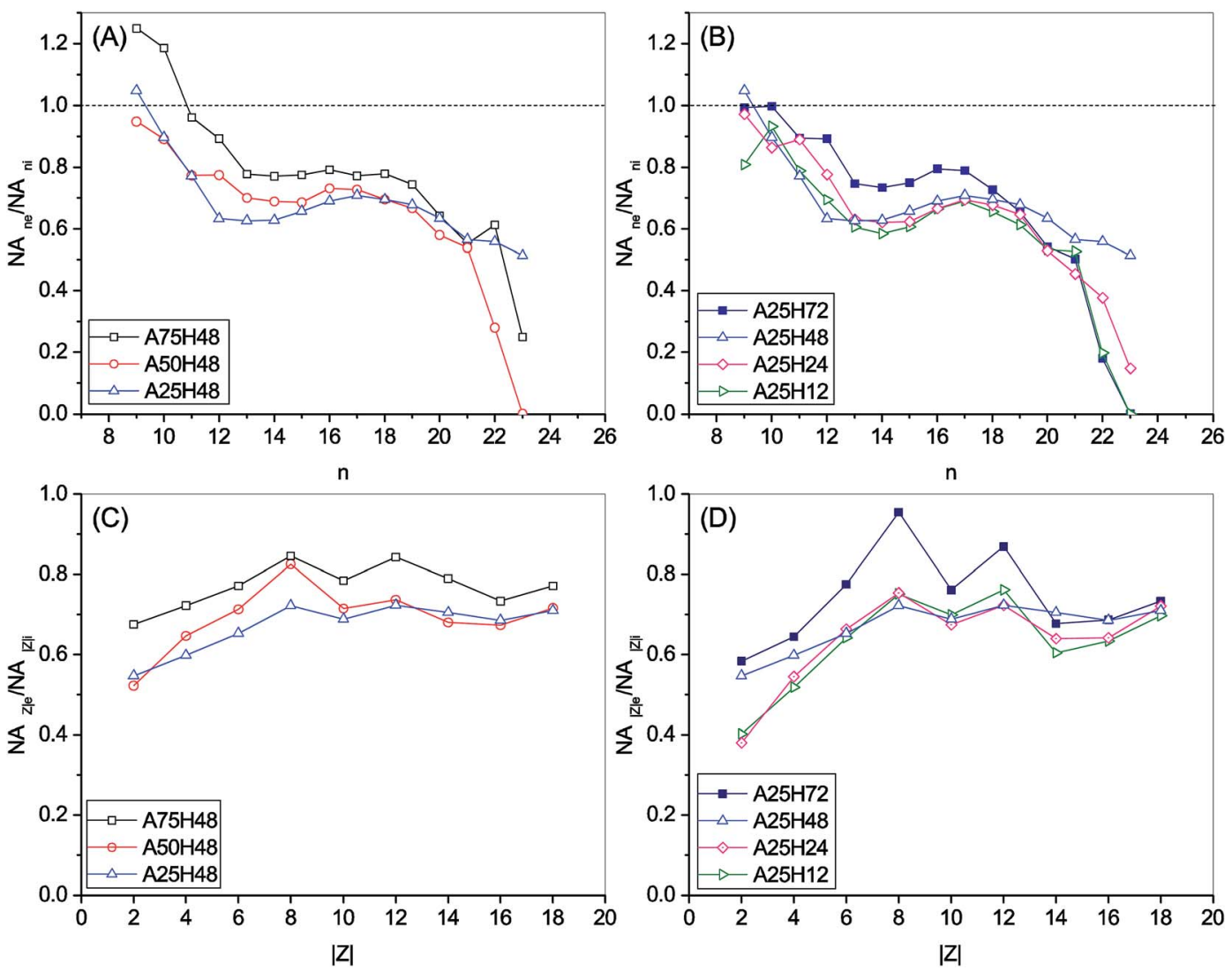

Fig. 1 The relative abundance of residual classical NAs with a carbon number $n\left(N A_{\sum n e} / N A_{\sum n i}\right)$ in the MBR permeate under different operating conditions: (A) HRT of $48 \mathrm{~h}$; (B) $25 \mathrm{mg} \mathrm{NH} 4-\mathrm{N}$ per $\mathrm{L}$ and $50 \mathrm{mg} \mathrm{NO} \mathrm{N}_{3}-\mathrm{N}$ per L. And the relative abundance of residual NAs with different cyclicity $\left(N A_{\sum|z| e} / N A_{\sum|z| i}\right)$ in the MBR permeate under different operating conditions: (C) HRT of $48 \mathrm{~h}$; (D) $25 \mathrm{mg} \mathrm{NH}{ }_{4}-\mathrm{N}_{\text {per }} \mathrm{L}$ and $50 \mathrm{mg} \mathrm{NO} \mathrm{N}_{3}-\mathrm{N}$ per $\mathrm{L}$.

configurations. In addition, it is noticed that, within each $Z$ series, some NAs with smaller carbon numbers (e.g., $n=9$ and $Z$ $=-6$ in Fig. 2) were even increased after biodegradation. It is thus suggested that some parent NAs with larger carbon numbers were biologically converted into NA species with smaller carbon numbers, which is consistent with our previous observation..$^{25,42}$

In Fig. $1 \mathrm{C}$ and $\mathrm{D}$, for $|Z|=2$ to 8 , the $\mathrm{NA}_{\sum|Z| \mathrm{e}} / \mathrm{NA}_{\sum|Z| \mathrm{i}}$ ratio is positively proportional to $|Z|$, whereas the $|Z|$ range of 9 to 18 witnesses a relatively stable region. It is noticed that within each $n$ series, an increased degree of cyclization (larger $|Z|$ ) generally resulted in poorer removal efficiency (Fig. 3 and $S 4 \dagger$ ). This trend is not surprising as the biodegradation rate of NAs decreased with increasing cyclicity in both of commercial NAs and OSPW NAs according to previous research. ${ }^{14}$ A reduction was observed for all the NAs with specific cyclicity (Fig. 1), which suggested the occurrence of ring cleavage. Some NAs (e.g. , $n=14$ and $|Z|=$ 10 in Fig. 3) were even enriched after biodegradation. Hence, it is speculated that microorganisms might convert some parent NAs with higher cyclicity into species with less rings. ${ }^{7,25,42}$

According to previous studies, the potential biodegradation pathways of aliphatic and alicyclic carboxylic acids include $\beta$ oxidation, combined $\alpha$ - and $\beta$-oxidation, and aromatization pathways. $^{\mathbf{1 4 , 4 7}}$ These researchers suggested that $\beta$-oxidation is the most probable degradation pathways of OSPW NAs in engineered biological systems. Quaternary and tertiary carbons, at $\beta$ or $\alpha$ position to the carboxylic group, would prevent or impede the proceeding of $\beta$-oxidation due to steric hindrance. This explains why the presence of alkyl branches and ring structures result in increased bio-resistance of NAs. In addition, it is claimed that a tertiary carbon in a ring is less favorable than tertiary carbons in an acyclic NAs as the ring creates further steric hindrance. Moreover, the previous researchers suggested that the intermediate product species generated during biodegradation of NAs could be even more recalcitrant to microbes depending on the occurrence and position of tertiary carbons. ${ }^{14}$ Furthermore, NAs with larger $n$ are generally more hydrophobic. ${ }^{48}$ Within the same $n$ series, a higher cyclicity tends to decrease the NA hydrophobicity. ${ }^{48}$ Organic compounds of higher hydrophobicity (or higher lipophilicity) could easily attach onto or penetrate the bacterial cell envelope, possibly leading to better biodegradation under certain circumstances. ${ }^{\mathbf{4 9}-51}$ For those particular species, stronger hydrophobic interactions of NAs-NAs, NAs-flocs, and NAs-fouling layer were expected, which would result in elevated local concentrations of hydrophobic NAs. And the locally elevated concentrations of NAs would benefit overall biodegradation of them as a threshold level of NAs exists for microorganisms to initiate the biodegradation process. ${ }^{52}$ 


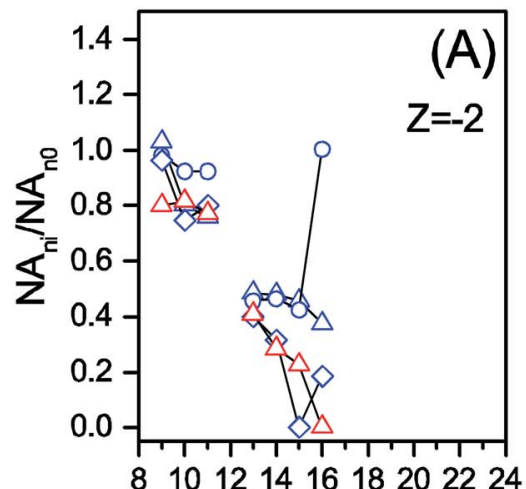

Carbon number $\mathrm{n}$

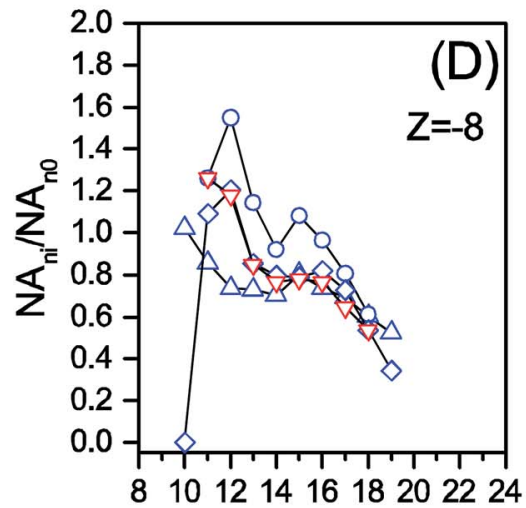

Carbon number $\mathrm{n}$

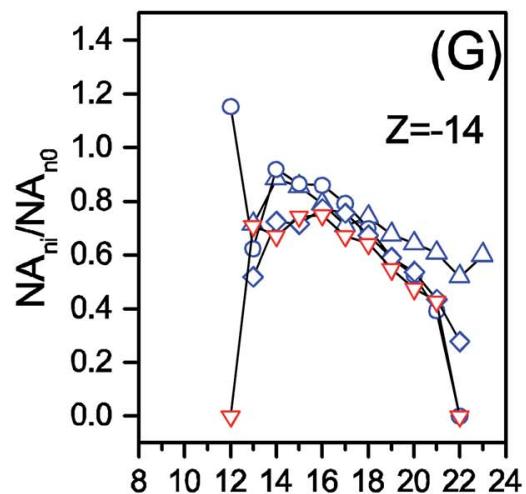

Carbon number $\mathrm{n}$

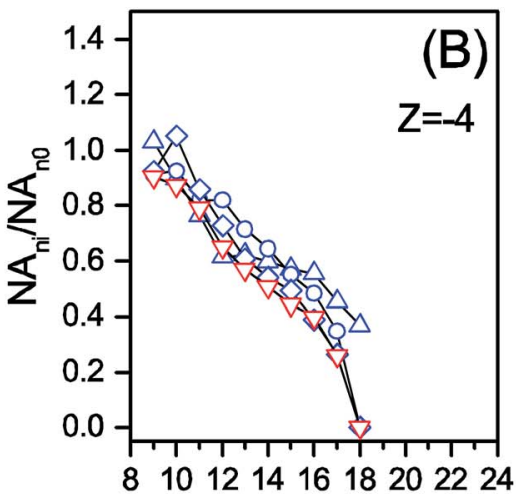

Carbon number $\mathrm{n}$

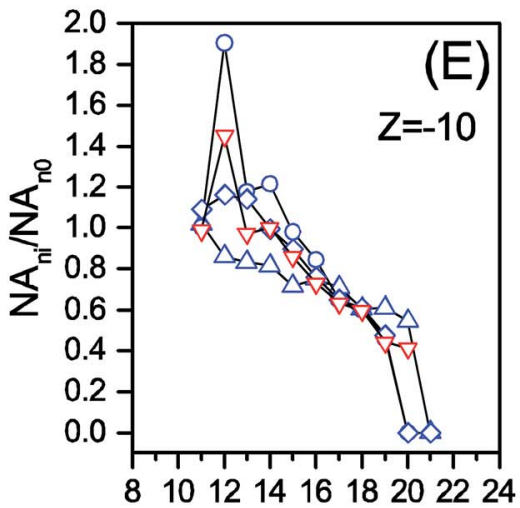

Carbon number $\mathrm{n}$

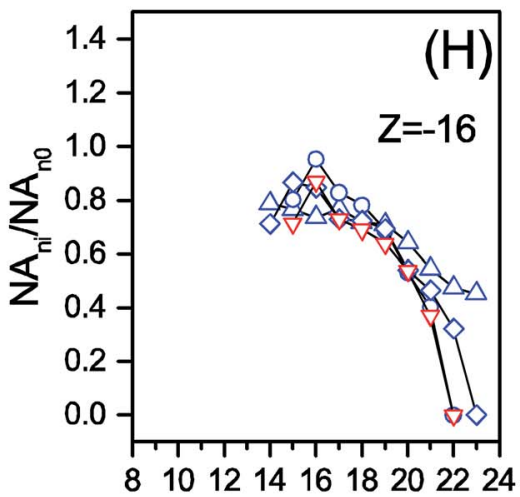

Carbon number $\mathrm{n}$

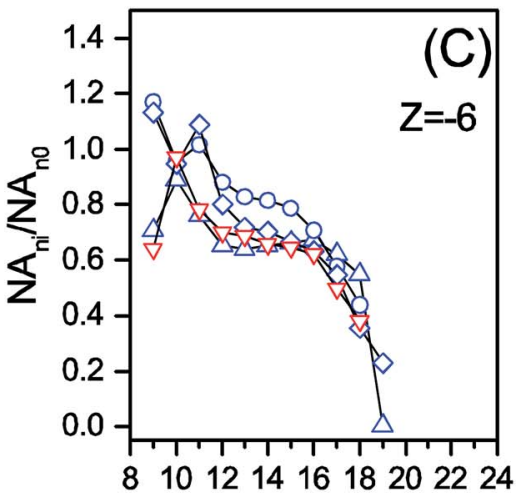

Carbon number $\mathrm{n}$

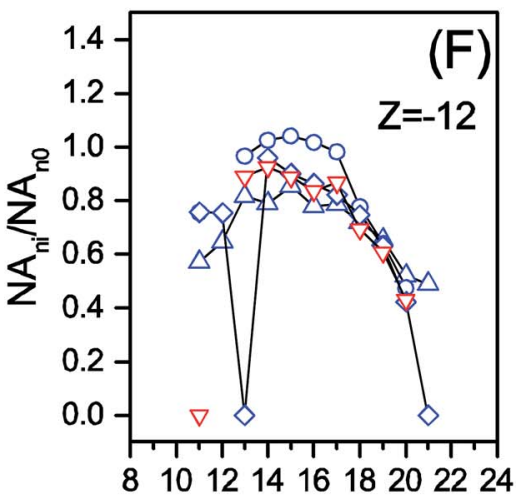

Carbon number $\mathrm{n}$

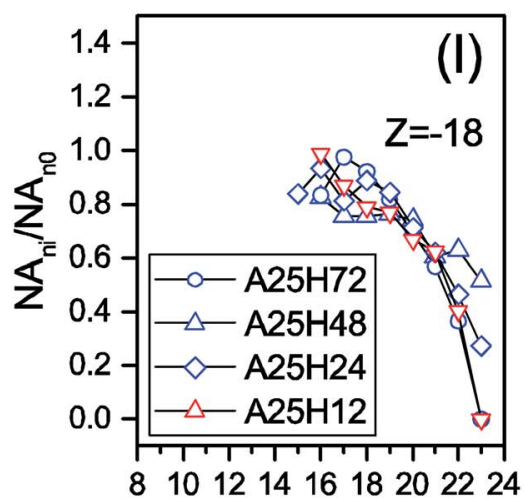

Carbon number $\mathrm{n}$

Fig. 2 The relative remaining abundance of NAs with different carbon numbers $\left(N A_{n i} / N A_{n 0}\right)$ within each $Z$ series of the permeate samples at different HRTs.

Oxy-NAs concentrations of the MBR feeds and permeates were also monitored (Fig. 4). O3 and O4 oxy-NAs are conceivably worth more attention than $\mathrm{O} 5$ and $\mathrm{O} 6$ oxy-NAs owing to their dominating abundance. $\mathrm{O} 4, \mathrm{O} 5$, and $\mathrm{O} 6$ oxy-NAs were all degraded to a certain extent at each stage. In contrast, more $\mathrm{O} 3$ oxy-NAs were generated after the MBR biological process at all stages except $\mathrm{A} 25 \mathrm{H} 48$ and A25H12. O3 (probably hydroxylated NAs) and O4 oxy-NAs (probably hydroxylated NAs) are intermediates during aerobic biodegradation of classical NAs., ${ }^{\mathbf{9 1 4 , 2 0 , 5 3 , 5 4}}$ According to Martin et al., O3 species may be byproducts of more cyclic classical NAs. ${ }^{9}$ The poorer removal of oxy-NAs might be attributed to the bioconversion of classical NAs. Some researchers reported unappreciable changes of $\mathrm{O} 3$ and $\mathrm{O} 4 \mathrm{oxy}-$ NAs after 98 days ${ }^{14}$ and 84 days ${ }^{55}$ of incubation. Therefore, the MBR in this study is competent for classical NAs and oxy-NA degradation. 


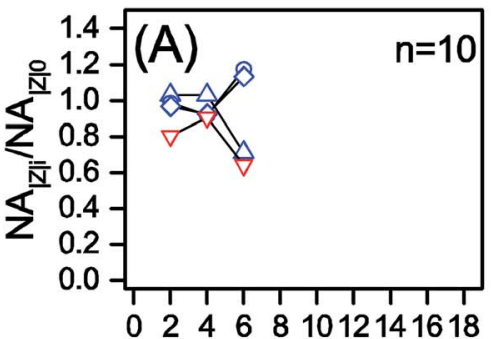

|Z|

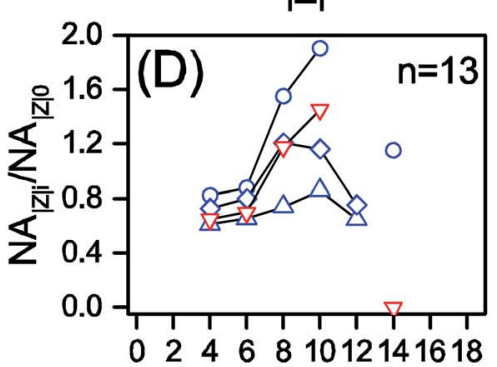

|Z|

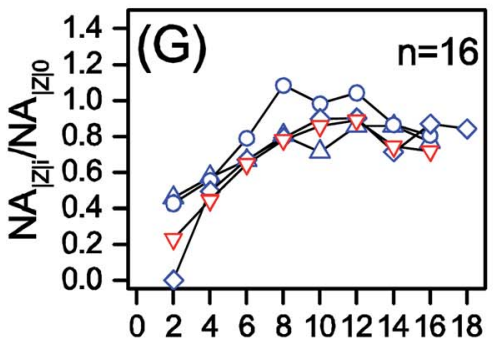

|Z|

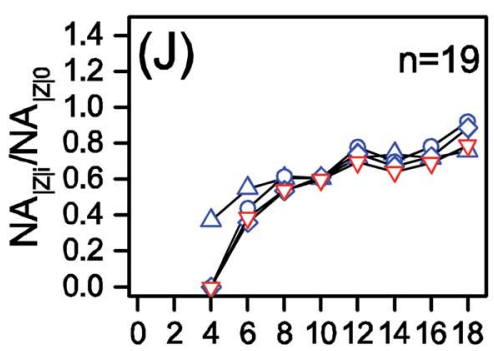

|Z|

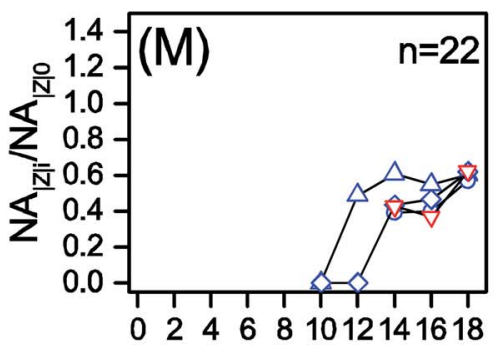

|Z|

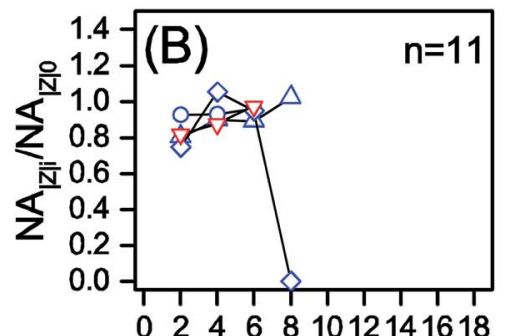

|Z|

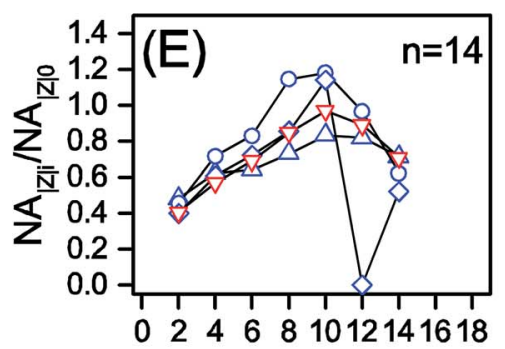

|Z|

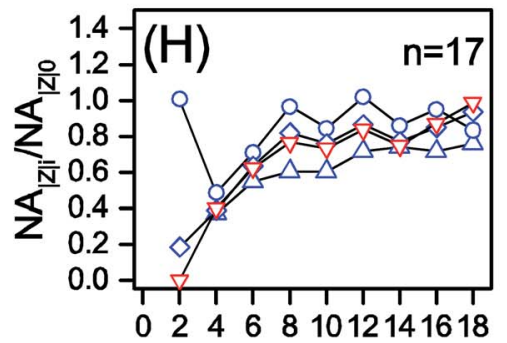

|Z|

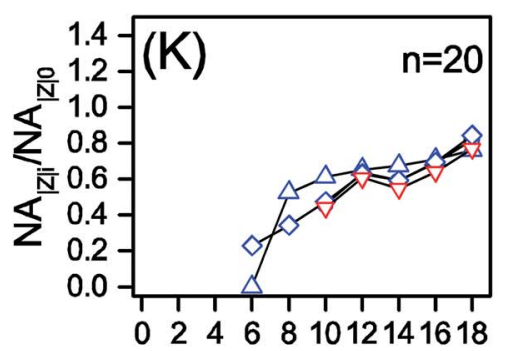

|Z|

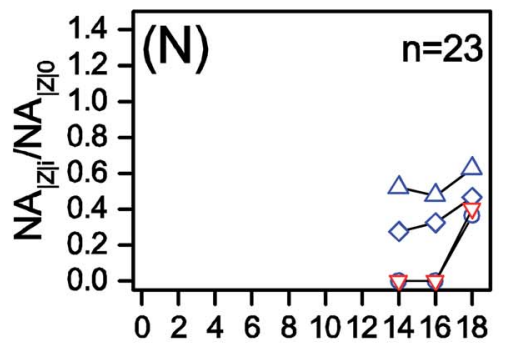

|Z|

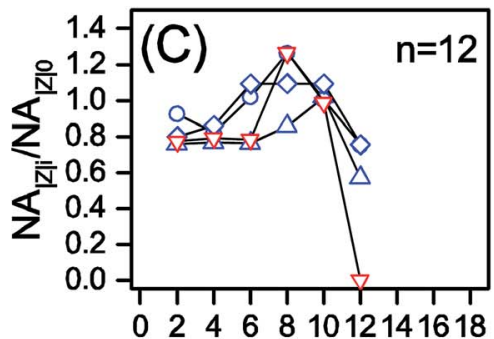

|Z|

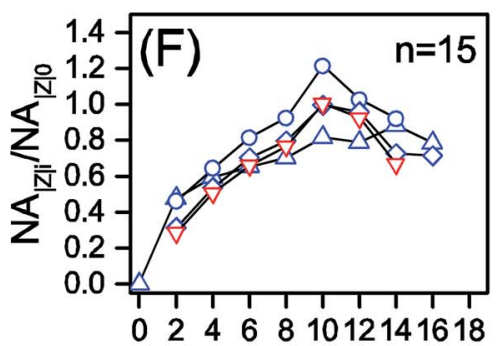

|Z|

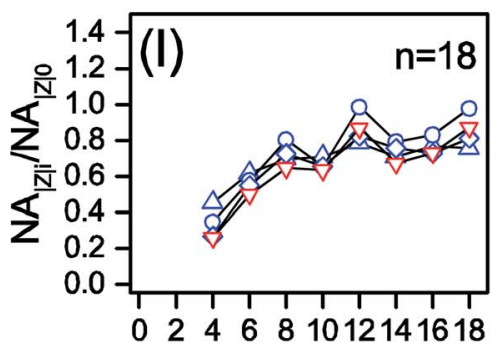

|Z]

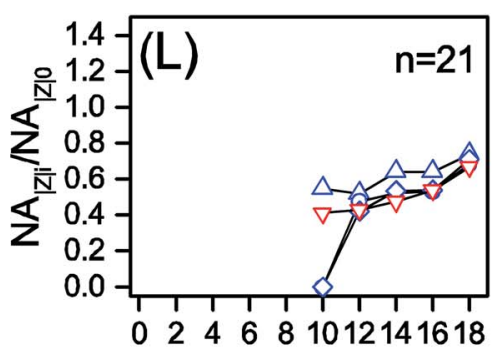

|Z|

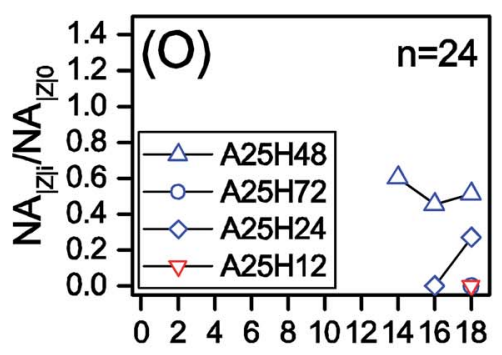

|Z|

Fig. 3 The relative remaining abundance of $N A$ s with different cyclicity $\left(N A_{Z i} / N A_{z 0}\right)$ within each $n$ series of the permeate samples at different HRTs.

3.1.1 Effect of supplemented nitrogen composition. Despite that the total concentration of $\mathrm{NH}_{4}-\mathrm{N}$ (including OSPW indigenous and supplemented $\mathrm{NH}_{4}-\mathrm{N}$ ) varied over the whole operation duration, the MBR constantly produced a permeate $\mathrm{NH}_{4}-\mathrm{N}$ concentration of $\sim 0 \mathrm{mg} \mathrm{L}^{-1}$ under all operating conditions, indicating its excellent ammonium oxidation stability 
(A)

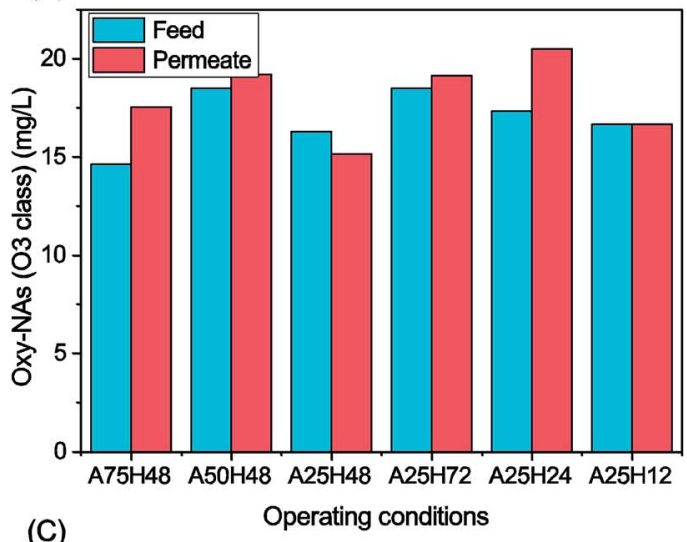

(C)

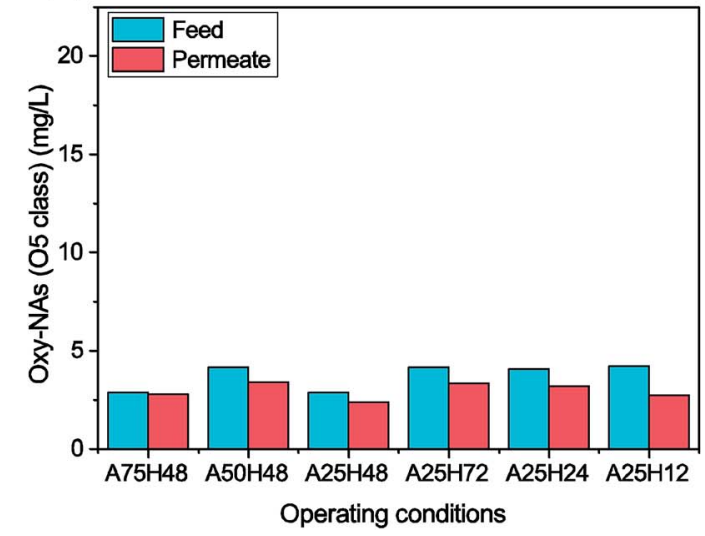

(B)

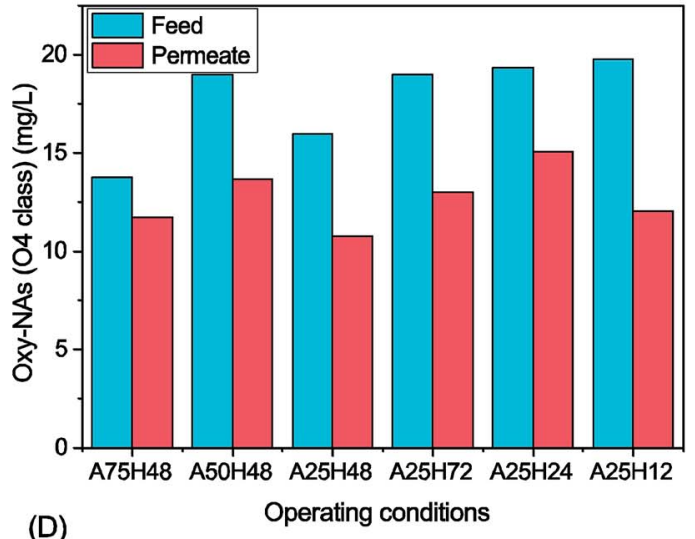

(D)

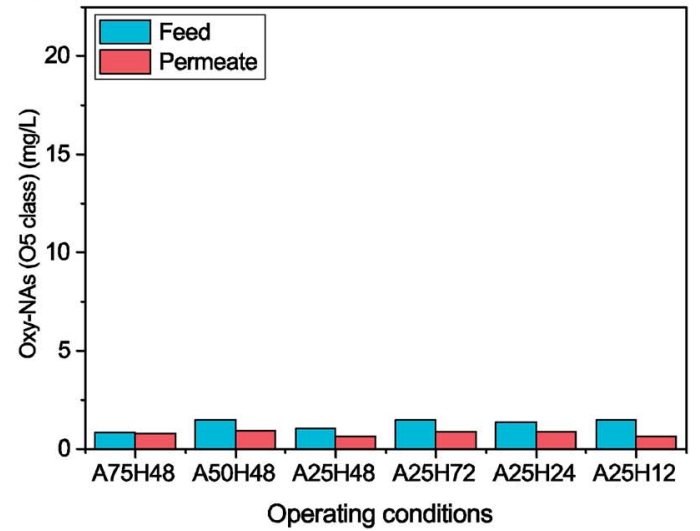

Fig. 4 Oxy-NA concentrations of the MBR feed and permeate under different operating conditions: (A) oxy-NAs with O3; (B) oxy-NAs with O4; (C) oxy-NAs with O5; and (D) oxy-NAs with O6.

(Tables $\mathrm{S} 1$ and $\mathrm{S} 2, \dagger$ and Fig. $\mathrm{S} 2 \dagger)$. The $\mathrm{NO}_{2}-\mathrm{N}$ concentrations of the MBR permeate were found negligible $(\leq 0.25 \mathrm{mg} \mathrm{N}$ per L) throughout the study (Fig. S2C $\dagger$ ), reflecting the insusceptibility of nitrite oxidizing microorganisms against operating condition variation. With respect to TIN removal performance, the MBR showed more fluctuations as the operating conditions changed, suggesting that denitrifiers might be more susceptible to changes of operating conditions and needed more time to adjust themselves. In addition to volatilization and biomass assimilation, the majority of $\mathrm{NH}_{4}-\mathrm{N}$ was oxidized into $\mathrm{NO}_{3}-\mathrm{N}$ by nitrifiers (Tables S1 and S2, $\dagger$ and Fig. S2 $\dagger$ ). The biomass changes over time are presented in Table S3. $\dagger$

Discussion within the following paragraphs will therefore be focused on how different influent $\mathrm{NH}_{4}-\mathrm{N}$ concentrations affected the MBR's efficiency in degrading OSPW NAs when the HRT was $48 \mathrm{~h}$.

Based on the removal efficiency of total classical NAs in Table 2, $\mathrm{NA}_{\sum n \mathrm{e}} / \mathrm{NA} A_{\sum n \mathrm{i}}$ and $\mathrm{NA} \mathrm{E}_{\sum|z| \mathrm{e}} / \mathrm{NA} \mathrm{A}_{\sum|Z| \mathrm{i}}$ in Fig. 1, A75H48 showed the lowest effectiveness for OSPW treatment, which may be attributed to the toxicity of free ammonia (FA) caused by high $\mathrm{NH}_{4}-\mathrm{N}$ concentration. It is known that a higher total ammonia $\left(\mathrm{NH}_{3}-\mathrm{N}\right.$ and $\left.\mathrm{NH}_{4}-\mathrm{N}\right)$ concentration under an alkaline $\mathrm{pH}$ environment results in a higher concentration of FA, which has been reported to be inhibitory to nitrifiers and other microbes. ${ }^{56,57}$ Based on Ford et al. 's study, ${ }^{58}$ an FA concentration of $\sim 13.5 \mathrm{mg} \mathrm{L}^{-1}$ is estimated in the MBR at $\mathrm{A} 75 \mathrm{H} 48$ stage.
In Fig. 1A, the two lines of A50H48 and A25H48 are weaved over the $n$ range. The difference between the lines for A50H48 and $\mathrm{A} 25 \mathrm{H} 48$ is insignificant $(P=0.3360>0.05)$. For NAs of C1217, A25H48 removed more NAs than A50H48 did, whereas the latter achieved higher removal of C9 and C20-23 NA species. Moreover, it is interesting to notice the residual abundance of C23 NAs at $\mathrm{A} 75 \mathrm{H} 48$ was lower than that at $\mathrm{A} 25 \mathrm{H} 48$. Therefore, it is suggested that higher concentrations of influent $\mathrm{NH}_{4}-\mathrm{N}$ might be helpful to degradation of NAs with higher carbon numbers (i.e., $n>21$ in this study). It is noticed that for $|Z|$ of 4 , 6,8 and $10, \mathrm{~A} 50 \mathrm{H} 48$ resulted in more $(P=0.034<0.05)$ residual NAs than A25H48 (Fig. 1C).

Among the three stages with an HRT of $48 \mathrm{~h}, \mathrm{~A} 25 \mathrm{H} 48$ was the only stage that reduced the $\mathrm{O} 3$ oxy-NAs, whereas A75H48 and A50H48 increased the abundance of that group of oxy-NAs by $20 \%$ and $4 \%$, respectively (Fig. 4). As for O4 oxy-NAs, A25H48 showed the best degradation (33\%). Regarding the removal of O5 and O6 oxy-NAs, A25H48 demonstrated either similar or higher performance than the other two stages.

Therefore, based on the higher removal rates of total classical NAs (33.7\%) and total oxy-NAs (20\%), the nitrogen composition used at $\mathrm{A} 25 \mathrm{H} 48(25 \mathrm{mg} \mathrm{NH}-\mathrm{N}$ per $\mathrm{L}$ and $50 \mathrm{mg}$ $\mathrm{NO}_{3}-\mathrm{N}$ per $\mathrm{L}$ ) was selected for further trials on different HRTs.

3.1.2 Effect of HRT. A25H72, A25H48, A25H24 and A25H12 are compared to evaluate the effect of HRT on OSPW NA degradation in the MBR. As indicated in Fig. 1B and D, NA $\sum_{\sum n e} /$ 
$\mathrm{NA}_{\sum n \mathrm{i}}$ at HRT of $12 \mathrm{~h}$ was significantly lower than those at HRT of $48 \mathrm{~h}(P=0.038<0.05)$ and $24 \mathrm{~h}(P=0.040<0.05)$. Among the four HRTs examined, the 48 hour HRT showed the poorest removal efficiency of NAs with higher carbon numbers (C1923), whereas 72 hour HRT and 12 hour HRT demonstrated a similarly good removal rate of C19-23 NAs. With respect to removal of NAs with different $Z$, the 72 hour HRT returned the worst removal efficiency for NAs with $|Z|$ within the range of 2 to 12. For $|Z|=2,4,14$ and 16, HRT of $48 \mathrm{~h}$ showed higher $\mathrm{NA}_{\sum|Z| \mathrm{e}} / \mathrm{NA}_{\sum|Z| \mathrm{i}}$ ratios than the 24 hour and 12 hour HRTs, indicating poorer removal efficiency at 48 hour HRT. For the rest $|Z|$ values, the difference among the HRTs of 48, 24 and $12 \mathrm{~h}$ was marginal. Within the whole $|Z|$ range, the difference of $\mathrm{NA}_{\sum|Z| \mathrm{e}} / \mathrm{NA}_{\sum|Z| \mathrm{i}}$ ratios between the HRTs of 24 and $12 \mathrm{~h}$ was insignificant $(P=0.671>0.05)$, indicating that the HRTs of 24 and $12 \mathrm{~h}$ made no difference in degrading NAs sharing the same cyclization degree.

No clear correlation between HRT and oxy-NA degradation rate could be elucidated based on the data in this study. Among the four stages, A25H12 exhibited the highest overall removal of oxy-NAs (O3 + O4 + O5 + O6) (23.9\%). Therefore, an HRT of $12 \mathrm{~h}$ is considered as the optimal on the basis of overall classical NA and oxy-NA removal.

Furthermore, it is not unconceivable that NA species with diverse molecular structures may have different bio-persistence, thus requiring different optimal operating conditions. Thousands of different NAs were present in the system, making it intricate to decipher the kinetics underlying. Previous researchers have reported enhancement of contaminant rejection performance by membrane biofouling. It has been suggested that the formation of biofouling may promote the microfiltration (MF) membrane rejection performance up to the nanofiltration (NF) efficiency. ${ }^{59}$ Solutes with higher molecular weights and more complex molecular structures tend to be better rejected by NF membrane.$^{60}$ In addition, it is apparent that the negatively charged deprotonated NA molecules confronted electrostatic repulsion from the membrane fouling layer. ${ }^{60}$ Thus, NAs could be either repelled or adsorbed by the fouling layer, depending on the permeate dragging force, hydrophobic interaction and electrostatic repulsion. In our study, HRT of 12 hours led to the removal of NA with higher hydrophobicity $(n>21$ and $|Z|<6)$ to a bigger extent (Fig. 1), suggesting the contribution of fouling layer. Microbial community structure analyses indicate that the potential major degraders of NAs were also abundantly present in the membrane's fouling layer (biofilm) (Section 3.2). Thus, the fouling layer formed on membrane surface may enhance the biodegradation of NAs through rejecting NAs thereby elevating the NAs concentration in the MBR sludge and on membrane surface. Organic and biological fouling in the MBR was not necessarily unfavorable in light of the improved NA degradation. It is therefore imperative to contain membrane fouling within a certain level to help mitigation of recalcitrant organic pollutants without significantly increasing the demand of chemical cleaning and membrane replacement. Further study could be performed to look into the influences of membrane/fouling-layer filtration on the removal of NAs in MBR.
Regarding the aquatic toxicity reduction, all six operating conditions effectively reduced the OSPW's inhibition effect to Vibrio fischeri (Fig. S5†). Although the best detoxification percentage (37\%) was achieved at the A25H12 stage based on the Microtox bioassay, the correlation between detoxification efficiency and NA (or oxy-NA) removal was vague. That is not unexpected as the acute toxicity is not only determined by NAs but also associated with other toxic organic compounds, such as aromatic compounds.

\subsection{Microbial community characterization}

Out of the great similarity caused by the internal recirculation between the anoxic and aerobic tanks, the OTU numbers of the two compartments were averaged for following analyses. As is shown in Fig. 5A-F, Rhodocyclales, Burkholderiales and Nitrosomonadales of the phyla Proteobacteria, Cytophagales, [Saprospirales] and Flavobacteriales of the phyla Bacteroidetes, Nitrospirales of the phyla Nitrospirae, and RB41 of the phyla Acidobacteria were arguably the most abundant microorganisms in the MBR throughout the whole operation.

It is found that the variations in relative abundances of some microbial species corresponded to the changes in MBR performance over the different operating conditions. The relative abundance of Rhodocyclales of sludge samples over the stages was positively correlated to the MBR's denitrification performance with an $r_{\mathrm{p}}$ of 0.790 . More interestingly, Rhodocyclales demonstrated strong positive correlations $\left(r_{\mathrm{p}}>0.700\right)$ to removal rates of C12-17 NAs and 3-4 ringed NAs (Tables S4 and $\mathrm{S} 5 \dagger)$. In comparison, Cytophagales showed positive correlations to removal rates of $\mathrm{C} 19-23$ NAs $\left(r_{\mathrm{p}} \geq 0.755\right)$ and $7-8$ ringed $\left(r_{\mathrm{p}} \geq\right.$ $0.680)$ NAs. In addition, relative abundances of Burkholderiales, RB41, and Deinococcales showed moderate positive correlation with removal rate of C23 classical NAs. It is, therefore, suggested that degradation of NAs with different molecular structures were completed by different microbial species either synergistically or independently. To confirm this, further effort should be made by using isolated bacterial cultures and model compounds.

Fig. 5G and $\mathrm{H}$ delineate the 10 most abundant bacterial orders of the two samples collected from membrane cake layers. All the major orders were commonly found in both of sludge samples and their corresponding cake layer samples. Some bacteria, such as Rhodocyclales and Cytophagales, were found more in the sludge samples, whereas some others, such as Nitrospirales, were more abundant in the cake layer samples. It is also found that the microbial community of membrane cake layer was affected by the suspended growth community. For instance, stage A25H24 witnessed more Rhodocyclales in both of sludge and cake layer microbial communities than stage A50H48 did. Furthermore, the similar dominant microorganisms in the sludge samples and their corresponding cake layer samples imply that the microorganisms inhabiting membrane cake layer might contribute to degradation of NAs given that biofilm systems have proven their effectiveness on OSPW NA degradation. ${ }^{21,45}$ 

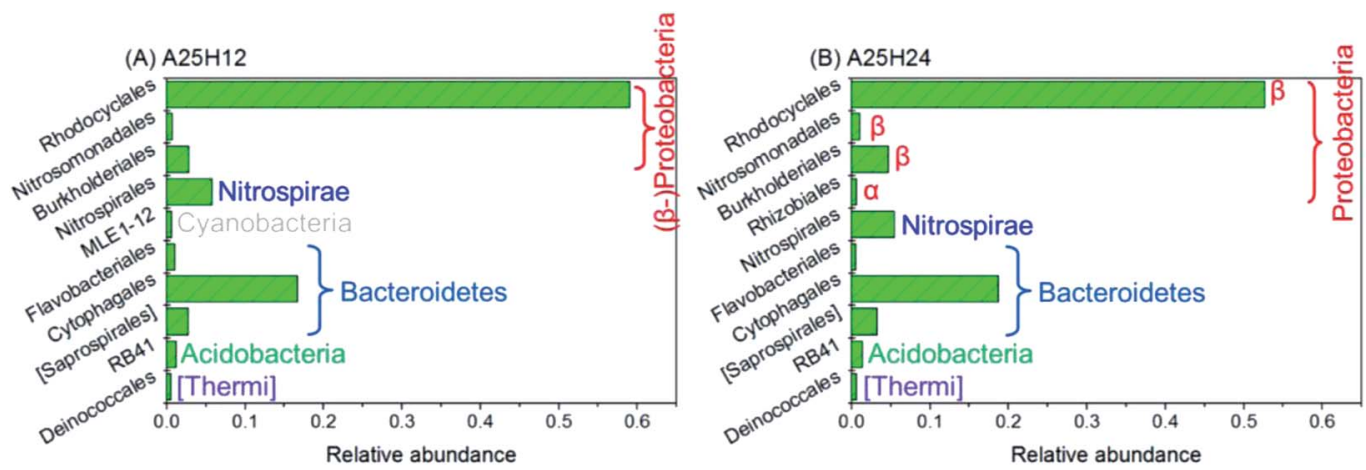

(C) $\mathrm{A} 25 \mathrm{H} 72$

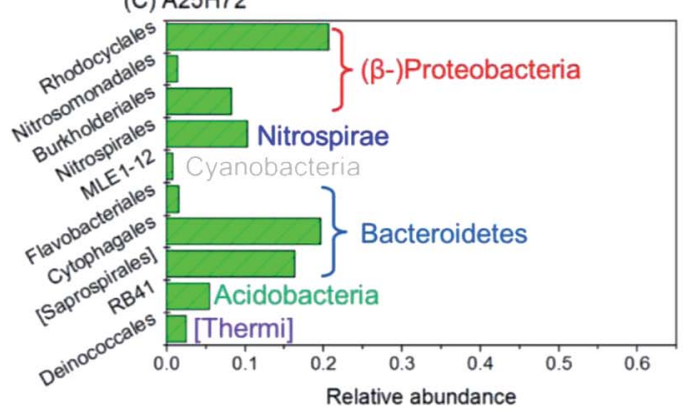

(E) $\mathrm{A} 50 \mathrm{H} 48$

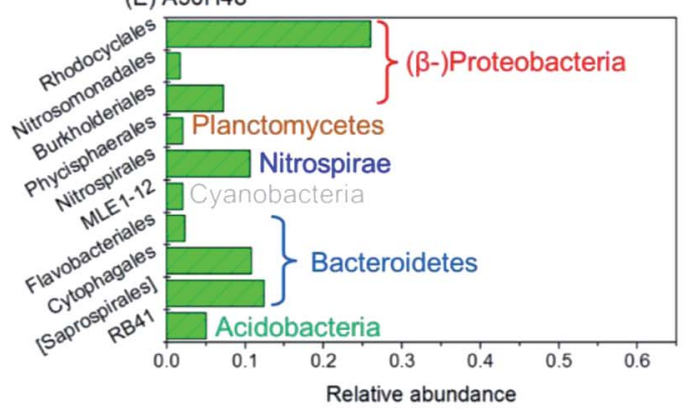

(G) A25H24 Cake

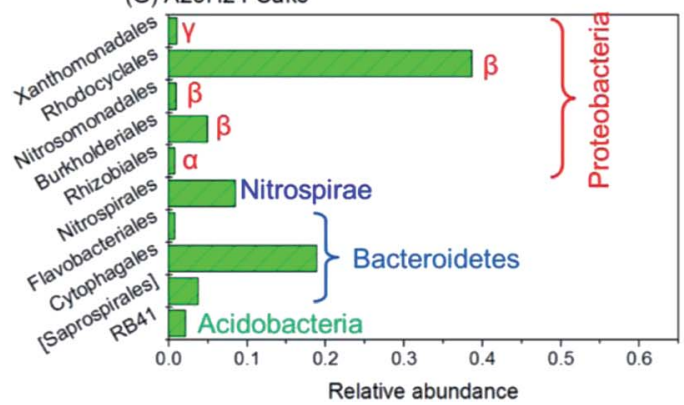

(D) $\mathrm{A} 25 \mathrm{H} 48$
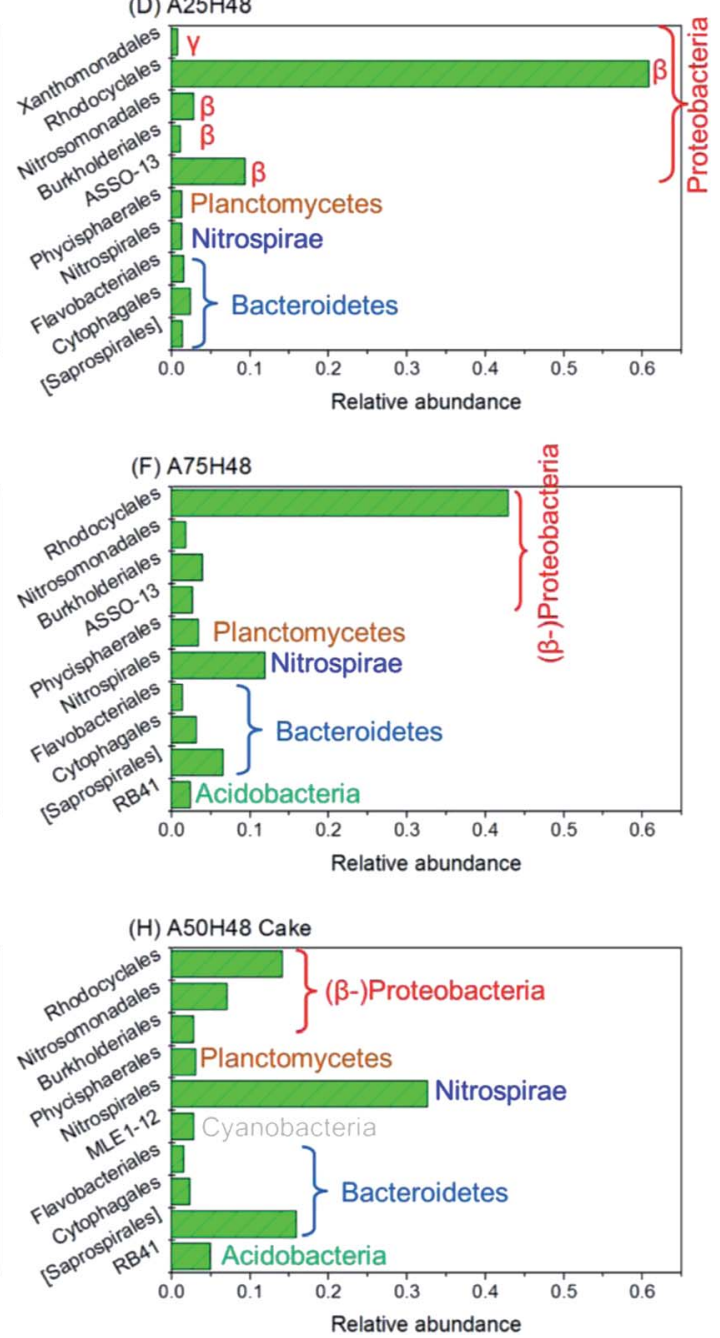

Fig. 5 The 10 most abundant orders detected in sludge samples from all operating stages (A-F) and membrane cake layer samples at stage $\mathrm{A} 25 \mathrm{H} 24$ and $\mathrm{A} 5 \mathrm{OH} 48$ ( $\mathrm{G}$ and $\mathrm{H}$ ) (note: square brackets indicate taxonomic changes recommended by Greengenes).

Researchers have reported dominating $\beta$-Proteobacteria in oil sands tailings ponds as degrader of NAs and aromatic hydrocarbons, ${ }^{61}$ which explains the high abundance of $\beta$-Proteobacteria detected in this study. Rhodocyclales are responsible for denitrification and degradation of aromatic

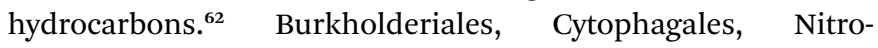
somonadales and Flavobacteriales have been linked to degradation of bio-recalcitrant hydrocarbons including NAs. ${ }^{63-69}$ The high population of Nitrosomonadales (ammonium oxidizers) and Nitrospirales (nitrite oxidizers) justifies the excellent nitrification performance of the MBR over the whole study.

Alpha diversity indices, Chao1, observed species, and Shannon were computed through rarefaction (Table S6†). A25H12 had the lowest bacterial richness among the six stages. It is interesting to notice that $5 \%$ of the count of genera constituted over $70 \%$ of the total bacterial abundance (Table S7 $\dagger$ ) for every 
operating condition, suggesting that the majority of the species richness was originated from numerically minor microbial species. Given that the A25H12 stage demonstrated the best classical and oxidized NA removal rates, it is suggested that numerically minor microbial species might not contribute to the MBR's NA degradation performance though their existence largely affected the species richness of the community. This is in accordance to previous research. ${ }^{70}$

The MBR also demonstrated excellent anti-fouling performance. The first severe fouling was not observed until after 433 days of continuous operation. Within the whole 742 day operation, only six severe fouling events occurred. Detailed results on membrane fouling behavior, major foulants, and fouling layer microbial community structure are available elsewhere. ${ }^{71}$

\section{Conclusion}

After more than one year of continuous operation, the MBR's performance on OSPW NA degradation was successfully improved through changing the supplemented inorganic nitrogen composition and HRT. The study showed that neither higher supplemented $\mathrm{NH}_{4}-\mathrm{N}$ concentrations nor longer HRTs guaranteed a better NA removal. Instead, an $\mathrm{NH}_{4}-\mathrm{N}$ concentration of $25 \mathrm{mg} \mathrm{L^{-1 }}$ and an HRT of $12 \mathrm{~h}$ demonstrated the best removal rates of total classical NAs $(37.6 \%)$ and total oxy-NAs (23.9\%). Classical NAs with larger carbon numbers were generally better mitigated in the MBR; and species with higher cyclicity were more persistent to microorganisms. Moreover, MiSeq sequencing analyses revealed that orders of Proteobacteria (e.g., Rhodocyclales and Burkholderiales), Bacteroidetes (e.g., Cytophagales and Flavobacteriales), and Nitrospirae (i.e., Nitrospirales) were the dominating microbial groups over the whole study duration though their relative abundances varied as the operating conditions changed. In the next stage, biofilm process would be added into the reactor to further enhance the removal efficiency. For instance, biodegradation of commercial NA model compounds has been studied based on biochar and granular activated carbon (GAC), which demonstrated quite encouraging performance. It is interesting to investigate whether the integration of bioadsorption into the MBR would enhance its OSPW NA degradation. ${ }^{72,73}$ Further efforts may also be made using model compounds and isolated bacteria cultures to verify the contribution and specificity of those microbes to degradation of NAs with certain molecular structural features. The findings from this study could be illuminating to future studies and projects on MBRs and other biological processes for not only OSPW treatment but also other impaired waters containing recalcitrant organic contaminants, such as shale gas produced water.

\section{Acknowledgements}

The authors acknowledge financial support for this project provided by research grants from the Helmholtz-Alberta Initiative (Theme 5) through the Alberta Environment and
Parks' ecoTrust Program and Meidensha Corporation (Y. L. and M. G. E. D.) and funding through an NSERC Industrial Research Chair Program in Oil Sands Tailings Water Treatment (M. G. E. D.) through the support by Syncrude Canada Ltd., Suncor Energy Inc., Shell Canada, Canadian Natural Resources Ltd., Total E\&P Canada Ltd., EPCOR Water Services, IOWC Technologies Inc., Alberta Innovates - Energy and Environment Solution, and Alberta Environment and Parks. The authors would also thank the help from Ms Shimiao Dong for her temporary participation in water quality measurement experiments.

\section{References}

1 CAPP, The facts on: oil sands, Canadian Association of Petroleum Producers, http://oilsandstoday.ca, 2014.

2 J. C. Anderson, S. B. Wiseman, N. Wang, A. Moustafa, L. Perez-Estrada, M. G. El-Din, J. W. Martin, K. Liber and J. P. Giesy, Environ. Sci. Technol., 2012, 46, 486-493.

3 J. S. Clemente and P. M. Fedorak, Chemosphere, 2005, 60, 585-600.

4 J. Headley and D. McMartin, J. Environ. Sci. Health, Part A: Environ. Sci. Eng., 2004, 39, 1989-2010.

5 D. C. Herman, P. M. Fedorak, M. D. MacKinnon and J. W. Costerton, Can. J. Microbiol., 1994, 40, 467-477.

6 J. Choi and Y. Liu, Int. Biodeterior. Biodegrad., 2014, 92, 7985.

7 G. Hwang, T. Dong, M. S. Islam, Z. Sheng, L. A. PérezEstrada, Y. Liu and M. G. El-Din, Bioresour. Technol., 2013, 130C, 269-277.

8 M. MacKinnon, T. V. Meer and A. Verbeek, Assessment of biological impact from a wet landscape option for the reclamation of fine tails from oil sands, Edmonton, 1993.

9 J. W. Martin, T. Barri, X. Han, P. M. Fedorak, M. G. El-Din, L. Perez, A. C. Scott and J. T. Jiang, Environ. Sci. Technol., 2010, 44, 8350-8356.

10 F. M. Holowenko, M. D. Mackinnon and P. M. Fedorak, Water Res., 2001, 35, 2595-2606.

11 M. S. Islam, J. Moreira, P. Chelme-Ayala and M. G. El-Din, Sci. Total Environ., 2014, 493, 282-290.

12 S. J. Rowland, A. G. Scarlett, D. Jones, C. E. West and R. A. Frank, Environ. Sci. Technol., 2011, 45, 3154-3159.

13 E. W. Allen, J. Environ. Eng. Sci., 2008, 7, 123-138.

14 X. Han, A. C. Scott, P. M. Fedorak, M. Bataineh and J. W. Martin, Environ. Sci. Technol., 2008, 42, 1290-1295.

15 A. C. Scott, M. D. Mackinnon and P. M. Fedorak, Environ. Sci. Technol., 2005, 39, 8388-8394.

16 F. M. Holowenko, M. D. MacKinnon and P. M. Fedorak, Water Res., 2002, 36, 2843-2855.

17 J. S. Clemente, M. D. MacKinnon and P. M. Fedorak, Environ. Sci. Technol., 2004, 38, 1009-1016.

18 R. A. Frank, H. Sanderson, R. Kavanagh, B. K. Burnison, J. V. Headley and K. R. Solomon, J. Toxicol. Environ. Health, Part A, 2009, 73, 319-329.

19 E. Quagraine, H. Peterson and J. Headley, J. Environ. Sci. Health, Part A: Environ. Sci. Eng., 2005, 40, 685-722. 
20 X. Han, M. D. MacKinnon and J. W. Martin, Chemosphere, 2009, 76, 63-70.

21 J. Choi, G. Hwang, M. G. El-Din and Y. Liu, Int. Biodeterior. Biodegrad., 2014, 89, 74-81.

22 G. Hwang, S. Kang, M. G. El-Din and Y. Liu, Colloids Surf., B, 2012, 91, 181-188.

23 N. S. A. Mutamim, Z. Z. Noor, M. A. A. Hassan, A. Yuniarto and G. Olsson, Chem. Eng. J., 2013, 225, 109-119.

24 Y. Tian, L. Chen, S. Zhang and S. Zhang, Chem. Eng. J., 2011, 168, 1093-1102.

25 J. Xue, Y. Zhang, Y. Liu and M. G. El-Din, Water Res., 2016, 88, 1-11.

26 G. Wen, J. Ma, L. Zhang and G. Yu, in Integrated Membrane Operations in Various Industrial Sectors, Case Studies, Elsevier B.V., 2010, pp. 195-209.

27 N. Fallah, B. Bonakdarpour, B. Nasernejad and M. A. Moghadam, J. Hazard. Mater., 2010, 178, 718-724.

28 S. R. P. Shariati, B. Bonakdarpour, N. Zare and F. Z. Ashtiani, Bioresour. Technol., 2011, 102, 7692-7699.

29 A. F. Viero and G. L. Sant'Anna, J. Hazard. Mater., 2008, 150, 185-186.

30 J.-S. Chang, C.-Y. Chang, A.-C. Chen, L. Erdei and S. Vigneswaran, Desalination, 2006, 191, 45-51.

31 J. Qin, M. Oo, G. Tao and K. Kekre, J. Membr. Sci., 2007, 293, 161-166.

32 J. Sipma, B. Osuna, N. Collado, H. Monclús, G. Ferrero, J. Comas and I. Rodriguez-Roda, Desalination, 2010, 250, 653-659.

33 F. Meng, B. Shi, F. Yang and H. Zhang, Bioprocess Biosyst. Eng., 2007, 30, 359-367.

34 X. Qu, W. Gao, M. Han, A. Chen and B. Liao, Sep. Sci. Technol., 2013, 48, 1529-1536.

35 Y. J. Chan, M. F. Chong, C. L. Law and D. G. Hassell, Chem. Eng. J., 2009, 155, 1-18.

36 B. De Gusseme, B. Pycke, T. Hennebel, A. Marcoen, S. E. Vlaeminck, H. Noppe, N. Boon and W. Verstraete, Water Res., 2009, 43, 2493-2503.

37 H. Roh, N. Subramanya, F. Zhao, C.-P. Yu, J. Sandt and K.-H. Chu, Chemosphere, 2009, 77, 1084-1089.

38 N. H. Tran, T. Urase and O. Kusakabe, J. Hazard. Mater., 2009, 171, 1051-1057.

39 J. Deni and M. J. Penninckx, Appl. Environ. Microbiol., 1999, 65, 4008.

40 W. Verstraete and S. Philips, Environ. Pollut., 1998, 102, 717726.

41 A. Anthonisen, R. Loehr, T. Prakasam and E. Srinath, Water Res., 1976, 835-852.

42 Y. Zhang, J. Xue, Y. Liu and M. G. El-Din, Chem. Eng. J., 2016, 302, 485-497.

43 H. Mahdavi, V. Prasad, Y. Liu and A. C. Ulrich, Bioresour. Technol., 2015, 187, 97-105.

44 J. Xue, Y. Zhang, Y. Liu and M. G. El-Din, Biodegradation, 2016, 27, 247-264.

45 C. Huang, Y. Shi, M. G. El-Din and Y. Liu, Water Res., 2015, 85, 167-176.
46 N. Wang, P. Chelme-Ayala, L. Perez-Estrada, E. GarciaGarcia, J. Pun, J. W. Martin, M. Belosevic and M. G. El-Din, Environ. Sci. Technol., 2013, 47, 6518-6526.

47 B. E. Smith, C. A. Lewis, S. T. Belt, C. Whitby and S. J. Rowland, Environ. Sci. Technol., 2008, 42, 9323-9328.

48 P. Pourrezaei, Doctor of Philosophy Dissertation, University of Alberta, 2013.

49 R. Peltola, Bioavailability aspects of hydrophobic contaminant degradation in soils, 2008.

50 S. N. Singh, Microbial degradation of xenobiotics, Springer, 2012.

51 J. Parsons and H. Govers, Ecotoxicol. Environ. Saf., 1990, 19, 212-227.

52 T. M. Misiti, U. Tezel, M. Tandukar and S. G. Pavlostathis, Water Res., 2013, 47, 5520-5534.

53 D. M. Grewer, R. F. Young, R. M. Whittal and P. M. Fedorak, Sci. Total Environ., 2010, 408, 5997-6010.

54 J. V. Headley, K. M. Peru, S. A. Armstrong, X. Han, J. W. Martin, M. M. Mapolelo, D. F. Smith, R. P. Rogers and A. G. Marshall, Rapid Commun. Mass Spectrom., 2009, 23, 515-522.

55 L. D. Brown, L. Pérez-Estrada, N. Wang, M. G. El-Din, J. W. Martin, P. M. Fedorak and A. C. Ulrich, Chemosphere, 2013, 93, 2748-2755.

56 B. Calli, B. Mertoglu, B. Inanc and O. Yenigun, Process Biochem., 2005, 40, 1285-1292.

57 S.-F. Yang, J.-H. Tay and Y. Liu, Biochem. Eng. J., 2004, 17, 4148.

58 D. L. Ford, R. L. Churchwell and J. W. Kachtick, Water Res., 1980, 2726-2746.

59 S. L. Khor, D. D. Sun, Y. Liu and J. O. Leckie, Process Biochem., 2007, 42, 1641-1648.

60 C. Bellona, J. E. Drewes, P. Xu and G. Amy, Water Res., 2004, 38, 2795-2809.

61 E. Yergeau, J. R. Lawrence, S. Sanschagrin, M. J. Waiser, D. R. Korber and C. W. Greer, Appl. Environ. Microbiol., 2012, 78, 7626-7637.

62 A. Loy, C. Schulz, S. Lücker, K. Stoecker, C. Baranyi, A. Lehner, M. Wagner, S. Lu and A. Scho, Appl. Environ. Microbiol., 2005, 71, 1373.

63 T. H. Bell, E. Yergeau, C. Maynard, D. Juck, L. G. Whyte and C. W. Greer, ISME J., 2013, 7, 1200-1210.

64 D. Pérez-Pantoja, R. Donoso, L. Agulló, M. Córdova, M. Seeger, D. H. Pieper and B. González, Environ. Microbiol., 2012, 14, 1091-1117.

65 W. F. Röling, M. G. Milner, D. M. Jones, K. Lee, F. Daniel, R. J. Swannell and I. M. Head, Appl. Environ. Microbiol, 2002, 68, 5537-5548.

66 X. Wang, M. Chen, J. Xiao, L. Hao, D. E. Crowley, Z. Zhang, J. Yu, N. Huang, M. Huo and J. Wu, PLoS One, 2015, 10, e0132881.

67 W. V. den Tweel, J. Smits and J. De Bont, Arch. Microbiol., 1988, 149, 207-213.

68 B. Cao, K. Nagarajan and K.-C. Loh, Appl. Microbiol. Biotechnol., 2009, 85, 207-228.

69 C. Whitby, Adv. Appl. Microbiol., 2010, 70, 93-125. 
70 J. Ma, Z. Wang, Y. Yang, X. Mei and Z. Wu, Water Res., 2013, 47, 859-869.

71 J. Xue, Y. Zhang, Y. Liu and M. G. El-Din, Water Res., 2016, 105, 444-455.
72 M. L. Frankel, T. I. Bhuiyan, A. Veksha, M. A. Demeter, D. B. Layzell, R. J. Helleur, J. M. Hill and R. J. Turner, Bioresour. Technol., 2016, 216, 352-361.

73 M. S. Islam, T. Dong, Z. Sheng, Y. Zhang, Y. Liu, M. G. El-Din and M. G. El-Din, Int. Biodeterior. Biodegrad., 2014, 91, 111118. 